\title{
Pengaruh Cekaman Kekeringan Terhadap Hasil dan Komponen Hasil Lima Kultivar Kedelai (Glycine max L.)
}

\section{Effects of Drought Stress on Yield and Yield Components of Five Soybean Cultivars (Glycine max L.)}

\author{
Nicki Heriyanto, Rohlan Rogomulyo*), Didik Indradewa \\ Departemen Budidaya pertanian, Fakultas Pertanian, Universitas Gadjah Mada \\ *) Penulis untuk koresponden Email: rohlan.rogomulyo@ugm.ac.id
}

\begin{abstract}
This research was conducted in a screenhouse on Banguntapan Tri Dharma Field, Faculty of Agriculture, Gadjah Mada University from April-July 2018. The experiment design that used was split plot factorial $5 \times 2$ with three replications. The main plot was watering that had two levels, watering everyday and watering every seven days. The sub plot was soybean cultivars that using five cultivars, Anjasmoro, Burangrang, Demas 1, Dering 1 and Devon 1. The data then tested using Tukey's Honest Significant Difference. Stress tolerance index (STI) was used to determine the cultivar which was more tolerant to drought stress. Drought stress reduced almost all of the yield components, such as number of pod, number of seed per pod and total grain weight by $39 \%, 2,73 \%$ and $52 \%$ respectively. Based on stress tolerance index, Demas 1 cultivar was the most tolerant to drought stress than Anjasmoro, Burangrang, Dering 1 and Devon cultivar.
\end{abstract}

Key words: Soybean, drought stress, yield, yield components, stress tolerance index

\section{INTISARI}

Penelitian dilakukan di rumah plastik di Kebun Tridharma Banguntapan, Fakultas Pertanian, Universitas Gadjah Mada, Yogyakarta dari bulan April-Juli 2018. Rancangan lingkungan yang dipakai adalah petak terbagi (split plot) faktorial 5x2 dengan tiga ulangan. Petak utama adalah pengairan yang terdiri dari dua aras yaitu disiram sehari sekali dan disiram tujuh hari sekali. Anak petak adalah kultivar kedelai yaitu kultivar Demas 1, Devon 1, Dering 1, Anjasmoro dan Burangrang. Analisis data menggunakan uji lanjut Beda Nyata Jujur (BNJ) Tukey. Penentuan kultivar tahan kekeringan menggunakan indeks ketahanan kekeringan yaitu Indeks Toleransi Cekaman (ITC). Cekaman kekeringan menyebabkan hampir semua variabel komponen hasil mengalami penurunan seperti jumlah polong, jumlah biji per polong, dan bobot total biji dengan rerata masing-masing penurunan sebesar 39\%, 2,73\%, dan 52\%. Berdasarkan indeks toleransi cekaman diperoleh informasi bahwa kultivar Demas 1 lebih tahan terhadap cekaman kekeringan dibandingkan dengan kultivar Devon 1, Dering 1, Burangrang dan kultivar Anjasmoro.

Kata kunci: Kedelai, cekaman kekeringan, hasil, komponen hasil, indeks toleransi cekaman 


\section{PENDAHULUAN}

Di Indonesia, sekitar 60\% area pertanaman kedelai diusahakan di lahan sawah pada musim kemarau (MK) II mengikuti pola tanam padi-padi kedelai, atau pada musim kemarau (MK) I mengikuti pola tanam padi-kedelai-kedelai (Subandi et al, 2007). Tanaman kedelai yang ditanam pada MK I sering mengalami kekeringan pada fase reproduktif, sedangkan pada MK II seluruh fase pertumbuhan kedelai tercekam kekeringan. Pada kondisi demikian, kedelai menghadapi risiko gagal panen (Suhartina et al, 2014).

Dibandingkan tanaman lainnya, kedelai memiliki tingkat kepekaan yang tinggi terhadap kekeringan. Hal ini yang menyebabkan sebagai salah satu faktor pembatas utama di daerah-daerah semi-arid (Maleki et al., 2013). Cekaman kekeringan secara tidak langsung menurunkan hasil kedelai dengan cara menurunkan komponen hasilnya. Fase pertumbuhan tanaman dan durasi dari cekaman kekeringan merupakan faktor yang penting untuk menentukan derajat dari dampak kekeringan terhadap pertumbuhan dan hasil akhir kedelai. Terjadinya kekurangan air dan suhu yang tinggi pada awal pembungaan ke pemasakan menyebabkan percepatan periode pengisian polong dan menurunkan bobot hasil (Kobraei et al., 2011). Kedelai lebih peka terhadap cekaman kekeringan selama fase reproduksi awal dibandingkan fase pertumbuhan lainnya. Cekaman kekeringan yang terjadi pada periode ini menyebabkan peningkatan keguguran polong, yang menyebabkan penurunan jumlah polong per tanaman, dan selanjutnya menurunkan hasil biji. Kekurangan air pada periode ini walaupun singkat dapat menurunkan pembentukan polong hingga $70 \%$. Hal ini disebabkan perkembangan reproduktif pada fase ini terdapat beberapa proses yang sangat rentan terhadap perubahan status air tanaman (Liu, 2004).

Beberapa indeks telah dikembangkan untuk mengevaluasi kultivar yang toleran terhadap kekeringan berdasarkan hasil biji seperti Mean Productivity (MP), Stress Susceptibility Index (SSI), Stress Tolerance Index (STI), Geometric Mean Productivity (GMP) dan Harmonic Mean Productivity (HARM). Abdipour et al (2008) melaporkan bahwa MP, GMP, HARM dan STI sebagai penentu yang paling baik untuk memisahkan genotipe-genotipe toleran kekeringan. Tint et al (2008) mengidentifikasi bahwa Stress Tolerance index (Indeks Toleransi Cekaman) sebagai penentu yang paling sesuai untuk digunakan sebagai alat identifikasi kultivar yang memiliki hasil lebih baik untuk lingkungan tercekam kekeringan. Indeks toleransi cekaman (ITC) merupakan penentu ketahanan kekeringan yang lebih baik karena dapat memilih genotipe-genotipe yang 
mempunyai hasil tinggi pada kondisi tercekam maupun tidak tercekam (Kargar et al, 2014).

Penelitian ini bertujuan untuk mengetahui pengaruh cekaman kekeringan terhadap hasil dan komponen hasil lima kultivar kedelai yang berbeda. Penelitian ini juga bertujuan untuk mengetahui kultivar kedelai yang paling tahan terhadap cekaman kekeringan dibandingkan dengan kultivar kedelai lainnya.

\section{BAHAN DAN METODE PENELITIAN}

Penelitian dilakukan di rumah plastik di Kebun Tridharma Banguntapan, Fakultas Pertanian, Universitas Gadjah Mada, Yogyakarta. Penelitian ini dilaksanakan dari bulan April sampai dengan bulan Juli 2018. Bahan-bahan yang digunakan dalam penelitian ini yaitu benih kedelai lima kultivar yang berasal dari Balitkabi (kultivar Dering 1, Anjasmoro, Devon 1, Demas 1, dan Burangrang). Alat yang digunakan dalam penelitian ini terdiri dari polibag ukuran $40 \mathrm{~cm} \times 40 \mathrm{~cm}$, Oven, timbangan analitik, moisture tester, sprayer, label, alat tulis dan plastik.

Rancangan perlakuan yang dipakai adalah faktorial 5x2 dengan tiga ulangan. Rancangan lingkungan yang digunakan adalah petak terbagi (split plot). Petak utama adalah pengairan yang terdiri atas dua aras yaitu disiram sehari sekali dan disiram tujuh hari sekali. Anak petak adalah kultivar kedelai terdiri dari kultivar Demas 1, Devon 1, Dering 1, Anjasmoro dan Burangrang. Variabel yang diamati yaitu jumlah dompol, jumlah polong, jumlah polong per dompol, jumlah biji per polong, bobot $100 \mathrm{biji}$, dan bobot total biji.

Analisis data dilakukan menggunakan uji ANOVA, apabila hasil uji ANOVA menunjukkan terdapat interaksi antara kedua faktor, dilakukan uji simple main effect. Apabila tidak terdapat interaksi antara kedua faktor dilakukan uji Honest Significant Difference (Beda Nyata Jujur) Tukey dengan taraf kepercayaan 95\%. Penentuan kultivar tahan cekaman kekeringan menggunakan indeks toleransi cekaman (ITC) dengan persamaan (Fernandez, 1992 cit. Zare, 2012):

$$
\mathrm{ITC}=\frac{Y s Y p}{\bar{Y} p^{2}}
$$

Keterangan:

Ys = Hasil biji dalam kondisi cekaman

$\mathrm{Yp}=$ Hasil biji dalam kondisi tidak tercekam/cukup air

$\bar{Y} p^{2} \quad=$ Rata-rata hasil biji dalam kondisi tercekam/cukup air 


\section{HASIL DAN PEMBAHASAN}

Pengamatan jumlah dompol per tanaman dilakukan pada saat panen dengan cara menghitung jumlah dompol atau sekumpulan polong pada setiap tanaman. Jumlah dompol per tanaman disajikan pada Tabel 1.

Tabel 1. Jumlah dompol lima kultivar kedelai pada kondisi cukup air dan pada kondisi kekeringan

\begin{tabular}{|c|c|c|c|}
\hline \multirow{2}{*}{ Kultivar } & \multicolumn{2}{|c|}{ Jumlah Dompol } & \multirow{2}{*}{ Rerata } \\
\hline & Cukup Air & Kekeringan & \\
\hline Anjasmoro & $38.83 \mathrm{bc}$ & $28.67 \mathrm{c}$ & 33.75 \\
\hline Burangrang & $44.00 \mathrm{bc}$ & $41.67 \mathrm{bc}$ & 42.84 \\
\hline Demas 1 & $107.33 \mathrm{a}$ & $52.50 \mathrm{bc}$ & 79.92 \\
\hline Dering 1 & $61.33 \mathrm{~b}$ & $44.67 \mathrm{bc}$ & 53.00 \\
\hline Devon 1 & $43.00 \mathrm{c}$ & $35.83 \mathrm{bc}$ & 39.42 \\
\hline Rerata & 58.9 & 40.67 & $(+)$ \\
\hline CV (\%) & & 22.7 & \\
\hline
\end{tabular}

Keterangan: Angka yang diikuti notasi sama pada kolom dan baris yang sama menunjukkan tidak berbeda nyata pada uji lanjut Beda Nyata Jujur Tukey (BNJ Tukey) dengan taraf kepercayaan 95\%. (+): ada interaksi.

Komponen hasil tanaman kedelai seperti jumlah dompol terpengaruh saat tanaman kedelai terkena cekaman kekeringan. Berdasarkan hasil pengamatan jumlah dompol, terdapat interaksi antara perlakuan cekaman kekeringan dengan kultivar (Tabel 1). Kultivar yang memiliki jumlah dompol lebih banyak pada kondisi cukup air seperti kultivar Demas 1, terjadi penurunan jumlah dompol yang nyata pada saat terkena cekaman kekeringan. Kultivar yang memiliki jumlah dompol yang lebih sedikit pada saat kondisi cukup air seperti kultivar kedelai Anjasmoro, Burangrang, Dering 1 dan Devon 1 menunjukkan tidak berbeda nyata pada saat terkena cekaman kekeringan.

Cekaman kekeringan secara nyata menurunkan komponen hasil kedelai yang berupa jumlah polong (Tabel 2). Kedelai yang ditanam pada kondisi kekeringan memiliki jumlah polong yang lebih sedikit dan berbeda nyata dengan kedelai yang ditanam pada kondisi cukup air. Cekaman kekeringan menyebabkan jumlah polong mengalami penurunan sebesar 39\% pada kondisi kekeringan dibandingkan dengan pada saat cukup air. Berkurangnya jumlah polong pada saat tanaman kedelai terkena cekaman kekeringan diindikasikan karena banyaknya bunga yang gugur sehingga bunga tersebut tidak dapat berkembang menjadi polong ataupun banyak polong yang gugur setelah bunga tersebut berkembang menjadi polong. Hal ini juga disampaikan oleh Hapsoh (2003) bahwa kekurangan air pada saat fase pembungaan akan menyebabkan banyak bunga dan polong gugur serta biji yang dihasilkan lebih kecil. 
Heriyanto el al., / Vegetalika. 2019. 8(4): 227-236

Tabel 2. Jumlah polong lima kultivar kedelai

\begin{tabular}{|c|c|c|c|}
\hline \multirow{2}{*}{ Kultivar } & \multicolumn{2}{|c|}{ Jumlah Polong } & \multirow{2}{*}{ Rerata } \\
\hline & Cukup Air & Kekeringan & \\
\hline Anjasmoro & 102.50 & 58.00 & $80.25 b$ \\
\hline Burangrang & 106.17 & 82.17 & $94.17 \mathrm{~b}$ \\
\hline Demas & 306.83 & 177.17 & $242.00 \mathrm{a}$ \\
\hline Dering & 157.00 & 83.00 & $120.00 \mathrm{~b}$ \\
\hline Devon & 124.50 & 84.67 & $104.58 \mathrm{~b}$ \\
\hline Rerata & $159.40 \mathrm{a}$ & $97.00 \mathrm{~b}$ & $(-)$ \\
\hline CV (\%) & & 30.95 & \\
\hline
\end{tabular}

Kultivar Demas 1 memiliki jumlah polong yang paling banyak dibandingkan dengan kutivar lainnya (Tabel 2). Kultivar Anjasmoro memiliki jumlah polong yang paling sedikit, akan tetapi tidak berbeda nyata dengan kultivar Burangrang, Dering 1 dan juga kultivar Devon 1. Hasil pengamatan jumlah polong kosong menunjukkan bahwa kultivar Demas 1 memiliki jumlah polong kosong yang lebih banyak dan berbeda nyata dibandingkan dengan kultivar Anjasmoro, Burangrang, Dering 1 maupun kultivar Devon 1.

Hasil pengamatan jumlah polong per dompol lima kultivar kedelai menunjukkan adanya interaksi antara perlakuan kekeringan dengan kultivar (Tabel 3).

Tabel 3. Jumlah polong per dompol lima kultivar kedelai saat panen

\begin{tabular}{|c|c|c|c|}
\hline \multirow{2}{*}{ Kultivar } & \multicolumn{2}{|c|}{ Jumlah Polong/Dompol } & \multirow{2}{*}{ Rerate } \\
\hline & Cukup Air & Kekeringan & \\
\hline Anjasmoro & $2.64 \mathrm{abc}$ & $2.00 \mathrm{dc}$ & 2.32 \\
\hline Burangrang & $2.39 \mathrm{bcd}$ & $1.99 \mathrm{dc}$ & 2.19 \\
\hline Demas 1 & $2.86 a b$ & $3.23 \mathrm{a}$ & 3.05 \\
\hline Dering 1 & $2.57 \mathrm{abcd}$ & $1.82 \mathrm{~d}$ & 2.19 \\
\hline Devon 1 & $2.90 \mathrm{ab}$ & $2.33 \mathrm{bcd}$ & 2.62 \\
\hline Rerata & 2.67 & 2.28 & $(+)$ \\
\hline CV (\%) & & 12 & \\
\hline
\end{tabular}

Jumlah polong per dompol antara tanaman pada kondisi cukup air dengan jumlah polong per dompol tanaman pada kondisi kekeringan tidak menunjukkan perbedaan yang nyata (Tabel 3). Jumlah polong per dompol dari lima kultivar kedelai menunjukkan tidak berbeda nyata pada saat kondisi cukup air. Perbedaan jumlah polong antar kultivar terjadi pada saat tanaman pada saat terkena cekaman kekeringan. Kultivar Demas 1 menunjukkan bahwa kultivar tersebut memiliki jumlah polong per dompol yang lebih banyak dibandingkan dengan kultivar lainnya pada saat kondisi kekeringan. Keempat 
kultivar lainnya menunjukkan penurunan jumlah polong per dompol, akan tetapi keempat kultivar tersebut tidak menunjukkan perbedaan yang nyata pada saat kondisi cukup air dengan kondisi kekeringan.

Cekaman kekeringan menyebabkan perbedaan jumlah biji per polong. Cekaman kekeringan menyebabkan penurunan jumlah biji per polong secara nyata (Tabel 4). Cekaman kekeringan menyebabkan jumlah biji per polong mengalami penurunan dengan rerata penurunan sebesar $2,73 \%$. Jumlah biji per polong perlakuan kekeringan menunjukkan jumlah biji per polong yang dihasilkan lebih sedikit dan berbeda nyata daripada perlakuan cukup air.

Tabel 4. Jumlah biji per polong lima kultivar kedelai

\begin{tabular}{|c|c|c|c|}
\hline \multirow{2}{*}{ Kultivar } & \multicolumn{2}{|c|}{ Jumlah Biji/Polong } & \multirow{2}{*}{ Rerata } \\
\hline & Cukup Air & Kekeringan & \\
\hline Anjasmoro & 2.16 & 2.02 & $2.09 \mathrm{ab}$ \\
\hline Burangrang & 1.95 & 1.66 & $1.81 \mathrm{bc}$ \\
\hline Demas & 1.83 & 1.72 & $1.78 \mathrm{c}$ \\
\hline Dering & 2.17 & 2.26 & $2.22 \mathrm{a}$ \\
\hline Devon & 1.98 & 2.15 & $2.07 \mathrm{ab}$ \\
\hline Rerata & $2.02 \mathrm{a}$ & $1.96 \mathrm{~b}$ & $(-)$ \\
\hline CV (\%) & & 7.97 & \\
\hline
\end{tabular}

Pengamatan jumlah biji per polong menunjukkan bahwa kultivar Dering 1 memiliki jumlah biji per polong paling banyak dibandingkan kultivar Burangrang dan kultivar Demas 1, akan tetapi tidak berbeda nyata dengan kultivar Anjasmoro dan kultivar Devon 1. Hal ini menunjukkan bahwa ukuran polong kultivar Anjasmoro, Dering 1 dan Devon 1 lebih besar daripada polong kultivar Demas 1.

Tabel 5. Bobot total biji lima kultivar kedelai

\begin{tabular}{|c|c|c|c|}
\hline \multirow{2}{*}{ Kultivar } & \multicolumn{2}{|c|}{ Bobot Total Biji (g) } & \multirow{2}{*}{ Rerata } \\
\hline & Cukup Air & Kekeringan & \\
\hline Anjasmoro & 34.49 & 13.35 & $23.92 \mathrm{~b}$ \\
\hline Burangrang & 33.71 & 16.87 & $25.29 b$ \\
\hline Demas & 54.70 & 24.80 & $39.75 \mathrm{a}$ \\
\hline Dering & 38.13 & 18.88 & $28.51 \mathrm{ab}$ \\
\hline Devon & 36.13 & 19.88 & $28.00 \mathrm{ab}$ \\
\hline Rerata & $39.43 \mathrm{a}$ & $18.76 \mathrm{~b}$ & $(-)$ \\
\hline CV (\%) & & 23.67 & \\
\hline
\end{tabular}

Hasil pengamatan bobot total biji lima kultivar kedelai menunjukkan perlakuan kekeringan memberikan pengaruh yang nyata terhadap bobot biji (Tabel 5). Perlakuan 
kekeringan menyebabkan hasil bobot biji yang lebih ringan dibandingkan dengan perlakuan cukup air. Cekaman kekeringan menyebabkan penurunan bobot total biji dengan rerata penurunan sebesar $52 \%$.

Hasil pengamatan bobot total biji dari lima kultivar kedelai (Tabel 5) menunjukkan bahwa kultivar Demas 1 memiliki bobot total biji yang lebih berat dibandingkan dengan kultivar Anjasmoro dan Burangrang, akan tetapi tidak berbeda nyata dengan kultivar Dering 1 dan kultivar Devon 1.

Kultivar yang memiliki bobot 100 biji yang cenderung lebih ringan pada saat kondisi cukup air seperti kultivar Anjasmoro, Demas 1, Dering 1 dan Devon 1 tidak mengalami penurunan bobot 100 biji yang nyata. Kultivar yang menunjukkan perbedaan pada pengamatan bobot 100 biji adalah kultivar Burangrang, yaitu bobot 100 biji kultivar tersebut menjadi lebih ringan (Tabel 6).

Tabel 6. Bobot 100 biji lima kultivar kedelai pada kondisi cukup air dan kekeringan

\begin{tabular}{|c|c|c|c|}
\hline \multirow{2}{*}{ Kultivar } & \multicolumn{2}{|c|}{ Bobot 100 Biji (g) } & \multirow{2}{*}{ Rerata } \\
\hline & Cukup Air & Kekeringan & \\
\hline Anjasmoro & $15.86 \mathrm{ab}$ & $12.41 \mathrm{bcd}$ & 14.14 \\
\hline Burangrang & $16.84 \mathrm{a}$ & $11.77 \mathrm{~cd}$ & 14.31 \\
\hline Demas 1 & $9.24 \mathrm{de}$ & 8.15 e & 8.69 \\
\hline Dering 1 & $10.86 \mathrm{cde}$ & $10.57 \mathrm{de}$ & 10.72 \\
\hline Devon 1 & $14.38 \mathrm{abc}$ & $11.71 \mathrm{~cd}$ & 13.05 \\
\hline Rerata & 13.44 & 10.92 & $(+)$ \\
\hline CV (\%) & & 8.61 & \\
\hline
\end{tabular}

Keterangan: Angka yang diikuti notasi sama pada kolom dan baris yang sama menunjukkan tidak berbeda nyata pada uji lanjut Beda Nyata Jujur Tukey (BNJ Tukey) dengan taraf kepercayaan 95\%. (+): ada interaksi.

Berdasarkan deskripsi varietas oleh Balitkabi (2016), kultivar Anjasmoro memiliki bobot 100 biji berkisar antara 14,8 gram hingga 15,3 gram, kultivar Burangrang memiliki bobot 100 biji kurang lebih 17 gram dan termasuk memiliki biji berukuran besar, kultivar Dering 1 memiliki bobot 100 biji 10,7 gram dan kultivar Devon 1 memiliki bobot 100 biji kurang lebih 14,3 gram.

Penentuan kultivar yang lebih tahan terhadap cekaman kekeringan dibandingkan dengan kultivar lainnya menggunakan indeks toleransi cekaman (ITC). Kultivar yang memiliki nilai indeks toleransi cekaman yang tinggi menunjukkan bahwa kultivar tersebut lebih tahan terhadap cekaman kekeringan dibandingkan dengan kultivar lainnya. Kultivar yang memiliki indeks toleransi cekaman yang lebih tinggi menunjukkan bahwa kultivar tersebut memiliki hasil biji yang lebih banyak pada kondisi tercekam dan pada kondisi optimal (Mohammadi et al., 2010). 
Tabel 7. Hasil penghitungan ketahanan kultivar kedelai berdasarkan indeks toleransi cekaman (ITC)

\begin{tabular}{lll}
\hline & Kultivar & ITC \\
\hline Anjasmoro & & 0,30 \\
Burangrang & & 0,38 \\
Demas 1 & 0,84 \\
Dering 1 & 0,45 \\
Devon 1 & 0,46 \\
\hline
\end{tabular}

Keterangan: ITC=Indeks Toleransi Cekaman

Beberapa indeks telah dikembangkan untuk mengevaluasi genotipe-genotipe yang toleran terhadap kekeringan berdasarkan hasil biji seperti Mean Productivity (MP), Stress Susceptibility Index (SSI), Stress Tolerance Index (STI), dan Geometric Mean Productivity (GMP). Pada penelitian ini hanya digunakan indeks toleransi cekaman (ITC) sebagai penentu kultivar yang lebih tahan terhadap cekaman kekeringan. Hal ini disebabkan indeks toleransi cekaman dapat menentukan genotipe-genotipe yang memiliki hasil tinggi pada kondisi tidak tercekam maupun dalam kondisi tercekam (Orcen dan Altinbas, 2014). Effendi et al. (2017) menentukan kriteria berdasarkan nilai indeks toleransi cekaman terhadap kekeringan adalah sebagai berikut:

1. Jika nilai ITC $\leq 0,5$, maka genotipe tersebut sangat peka terhadap cekaman kekeringan.

2. Jika nilai ITC $0,5<$ ITC $\leq 0,75$, maka genotipe tersebut peka terhadap cekaman kekeringan.

3. Jika nilai ITC $0,75<$ ITC $\leq 1$, maka genotipe tersebut moderat toleran terhadap cekaman kekeringan.

4. Jika nilai ITC>1, maka genotipe tersebut toleran terhadap cekaman kekeringan.

Tabel 7 menunjukkan hasil penghitungan nilai indeks toleransi cekaman (ITC) dari lima kultivar kedelai yang diuji. Berdasarkan kriteria oleh Effendi et al. (2017), kultivar Demas 1 termasuk ke dalam kultivar yang moderat toleran terhadap cekaman kekeringan (nilai ITC=0,84). Kultivar kedelai yang diuji lainnya seperti kultivar Anjasmoro, Burangrang, Dering 1 dan Devon 1 termasuk ke dalam kultivar yang sangat peka terhadap cekaman kekeringan dengan nilai indeks toleransi cekaman masingmasing sebesar 0,30, 0,38, 0,45 dan 0,46 (Tabel 7). 
Heriyanto el al., / Vegetalika. 2019. 8(4): 227-236

Tabel 8. Hasil peringkat ketahanan kultivar kedelai berdasarkan indeks toleransi cekaman (ITC)

\begin{tabular}{|c|c|}
\hline Kultivar & ITC \\
\hline Anjasmoro & 5 \\
\hline Burangrang & 4 \\
\hline Demas 1 & 1 \\
\hline Dering 1 & 3 \\
\hline Devon 1 & 2 \\
\hline
\end{tabular}

Keterangan: ITC=Indeks Toleransi Cekaman

Berdasarkan hasil pemeringkatan menggunakan indeks toleransi cekaman, diperoleh hasil bahwa kultivar Demas 1 merupakan kultivar yang paling tahan terhadap cekaman kekeringan dibandingkan dengan kultivar Anjasmoro, Burangrang, Dering 1 dan Devon 1 (Tabel 8). Kultivar Devon 1, Dering 1, dan Burangrang termasuk ke dalam golongan moderat serta kultivar Anjasmoro tergolong kultivar yang paling tidak tahan kekeringan.

\section{KESIMPULAN}

1. Cekaman kekeringan menyebabkan hampir semua variabel komponen hasil mengalami penurunan seperti jumlah polong, jumlah biji per polong, dan bobot total biji dengan rerata masing-masing penurunan sebesar $39 \%, 39,8 \%, 2,73 \%$, dan $52 \%$.

2. Berdasarkan indeks toleransi cekaman (ITC) diperoleh kesimpulan bahwa kultivar Demas 1 lebih tahan terhadap cekaman kekeringan dibandingkan dengan kultivar Devon 1, Dering 1, Burangrang dan kultivar Anjasmoro.

\section{DAFTAR PUSTAKA}

Abdipour, M., A.H. Razee, S. Hooshmand, dan G. Bagherifard. 2008. Evaluation of drought tolerance of indeterminate soybean genotypes in flowering and seed filling stages. Journal of Research in Agricultural Science 4(2): 140-150.

Balitkabi (Badan Penelitian Kacang dan Umbi). 2016. Deskripsi Varietas Unggul Kedelai. Badan Penelitian Kacang dan Umbi, Malang.

Effendi, R., Andi, T.M., dan Muhammad, A. 2017. Daya gabung inbrida jagung toleran cekaman kekeringan dan nitrogen rendah pada pembentukan varietas hibrida. Balai Penelitian Tanaman Serealia, Sulawesi Selatan.

Hapsoh. 2003. Kompatibilitas MVA dan beberapa genotipe kedelai pada beberapa tingkat cekaman kekeringan tanah ultisol: tanggap morfologi dan Hasil. Institut Pertanian Bogor, Bogor. Disertasi.

Kargar, S.M.A., A. Mostafaie, E.M. Hervan, S.S. Pourdad. 2014. Evaluation of soybean genotypes using drought stress tolerant indices. International Journal of Agronomy and Agricultural Research 5(2): 103-113. 
Kobraei, S., A. Etminan, R. Mohammadi, dan S. Kobraee. 2011. Effects of drought stress on yield and yield components of soybean. Annals of Biological Research 2(5): 504-509.

Liu, F. 2004. Physiological regulation of pod in soybean (Glycine max L. Merril.) during drought at early reproductive stages. The Royal Veterinary and Agricultural University, Copenhagen. Dissertation.

Maleki, A., A. Naderi, R. Naseri, A. Fathi, S. Bahamin dan R. Maleki. 2013. Physiological performance of soybean cultivars under drought stress. Bull. Env. Pharmacol. Life Sci. 2(6): 38-44.

Mohammadi, R., Armion, M., Kahrizi, D., and Amri, A. 2010. Efficiency of screening techniques for evaluating durum wheat genotypes under mild drought conditions. International Journal of Plant Production 4:11-24.

Orcen, N. and M. Altinbas. 2014. Use of some stress tolerance indices for late drought in spring wheat. Fesenius Environmental Bulletin 23: 2289-2294.

Subandi, A. Harosno dan H. Kuntyastuti. 2007. Areal Pertanman dan Sistem Produksi Kedelai di Indonesia. Balai Penelitian Tanaman Kacang-kacangan dan Umbiumbian, Malang.

Suhartina, Purwantoro, N. Nugrahaeni, dan A. Taufiq. 2014. Stabilitas Hasil Galur Kedelai Toleran Cekaman Kekeringan. Penelitian Pertanian Tanaman Pangan 33(1): 54-60.

Tint, A.M.M., E. Sarabool, S. Nakasathein, W. Chairee. 2011. Differential response of selected soybean cultivars to drought stress and their drought tolerant attributions. Natural Sci. 45(4): 571-582.

Zare, M. 2012. Evaluation of drought tolerance indices for the selection of Iranian barley (Hordeum vulgare) cultivars. African Journal of Biotechnology 11: 15975-15981. 